\title{
A atuação histórica do BNDES: o que os dados têm a nos dizer?
}

\author{
Historical performance of BNDES: \\ what can data tell us?
}

RICARDO DE MENEZES BARBOZA*

MAURICIO FURTADO $* *$

HUMBERTO GABRIELLI***,

\begin{abstract}
RESUMO: Este trabalho tem três objetivos. O primeiro é investigar a composição setorial dos desembolsos do BNDES desde a sua criação, em 1952, com base nos registros históricos de financiamento da instituição. O BNDES foi criado para ser o banco da infraestrutura nacional e, de fato, cumpriu esse papel na sua primeira década de existência. No entanto, a partir da década de 1960, a maior parte dos financiamentos do BNDES destinou-se para o setor industrial, ainda que de forma cadente ao longo do tempo. Apenas na década de 2010, a infraestrutura voltou a ser o setor protagonista nos empréstimos do banco. O segundo objetivo consiste em analisar o tamanho do BNDES na economia brasileira desde a sua criação. Para isso, são analisadas estatísticas de participação do banco no investimento agregado e no PIB. Os dados mostram que a instituição aumentou significativamente de tamanho na década de 2000, especialmente entre 2009 e 2014, quando superou o tamanho prevalecente na década de 1970, período marcado pelo II PND. O terceiro objetivo consiste em decompor os desembolsos do BNDES, desde 1990, por porte de empresa. Os dados revelam que grandes empresas têm sido cada vez menos - e não mais, como parece ser o senso comum - beneficiadas pelos empréstimos do banco. Isso quer dizer que micro, pequenas e médias empresas (MPMEs) têm ganhado cada vez mais participação no crédito concedido pelo BNDES.
\end{abstract}

PALAVRAS-CHAVE: BNDES; desembolsos; infraestrutura; indústria; investimento; MPMEs.

\footnotetext{
*Gerente do Departamento de Pesquisa Econômica do BNDES, Rio de Janeiro/RJ, Brasil. E-mail: ricardo.barboza@bndes.gov.br. Orcid 0000-0001-8952-8132.

* Economista do Departamento de Pesquisa Econômica do BNDES, Rio de Janeiro/RJ, Brasil. E-mail: mauricio.furtado@bndes.gov.br. Orcid 0000-0003-1003-2578.

**Administrador do Departamento de Produtos do BNDES. E-mail: humberto.gabrielli@bndes.gov.br. Orcid 0000-0002-2909-0092. Submetido: 31/Janeiro/2018; Aprovado: 10/Dezembro/2018.

${ }^{+}$As opiniões expressas neste trabalho são da exclusiva responsabilidade dos autores e não refletem necessariamente a opinião do BNDES ou de seus membros. Os autores agradecem a Fabio Giambiagi, João Marco Cunha, Felipe Maciel, Guilherme Tinoco, Gilberto Borça Jr., Victor Pina Dias, Paulo Faveret e Maurício Neves por comentários e sugestões.
} 
ABSTRACT: This paper has three objectives. First, to investigate the sectoral composition of Brazilian Development Bank (BNDES) loans since 1952, based on the institution's financing track record throughout its history. BNDES was created to be the bank of national infrastructure and did, in fact, played this role in its first decade of existence. However, from the 1960's onwards, the major part of the bank's loans was directed towards the industrial sector, even if in a decreasing manner along the course of time. Only in the 2010 decade did infrastructure return to be the focus of the bank's loans. The second objective consists in analyzing the size of the Bank relative to Brazilian aggregate investment and to GDP. The data shows that the institution significantly increased its size in the first decade of the 2000's, especially between 2009 and 2014, when it surpassed the size observed in the seventies, a period marked by the II PND. The third objective is to decompose BNDES loans by the size of the companies since 1990. Data reveals that big companies have been less and less - and not more, as common sense indicates - benefited by BNDES credit. This means that small and medium companies (SMEs) have gained an increasing share of BNDES loans in the last thirty years.

KEYWORDS: BNDES; disbursements; infrastructure; industry, investment; SMEs.

JEL Classification: N00; N2; N25; N40.

\section{INTRODUÇÃO}

Este artigo tem como objetivo examinar a atuação histórica do BNDES durante todo o período entre 1952 e 2017 , com base nos dados de aprovação e desembolso do banco. Em particular, três questões tentarão ser respondidas. Primeiro, é verdade que o BNDES representou, historicamente, o banco da infraestrutura nacional? Segundo, é verdade que o BNDES assumiu, na década de 2000, um tamanho maior do que o observado historicamente em termos de participação no PIB e no investimento? Terceiro, é verdade que o BNDES apoiou grandes empresas no seu passado mais recente, como nunca antes na sua história?

Antes de prosseguir, cabe uma advertência. A análise aqui realizada é estritamente positiva (e não normativa), retratando a realidade como ela foi (e não como ela deveria ter sido $)^{1}$. Isso quer dizer que se leva em consideração tão somente os dados disponíveis, que são imperfeitos e passíveis de crítica, mas ainda assim a melhor fonte de informação para a análise proposta.

Este artigo se insere em uma literatura bastante fragmentada sobre a atuação do banco. Por exemplo, o BNDES (1992) apresenta dados sobre os desembolsos e aprovações da instituição para o período de 1952 a 1991. Além (1998) investiga os desembolsos totais do banco de 1970 a 1997, bem como a composição setorial desses empréstimos entre 1980 e 1997. Monteiro Filha (1995) apresenta a participação anual dos desembolsos do BNDES na formação bruta de capital fixo. Giambiagi et al. (1994) analisam os desembolsos do BNDES na década de 2000. Mais

\footnotetext{
${ }^{1}$ Para exemplos de análises normativas envolvendo o BNDES, ver Musacchio et al. (2017) e Frischtak et al. (2017).
} 
recentemente, Machado e Roitman (2015), Barboza et al.. (2017), Machado, Grimaldi e Albuquerque (2018) e Ellery, Nascimento e Sachsida (2018) investigam os empréstimos do banco realizados no âmbito do Programa de Sustentação do Investimento (PSI).

Além disso, o artigo se relaciona com diversos trabalhos recentes que tratam da efetividade dos desembolsos do BNDES e justificam essa efetividade com argumentos relacionados ao porte ou à estrutura de capital das empresas apoiadas. Por exemplo, Machado et al. (2014) e Cavalcanti e Vaz (2017) encontram um impacto positivo e estatisticamente significativo do BNDES sobre o investimento de micro, pequenas e médias empresas. Oliveira et al. (2014), por sua vez, encontram efeito relevante do crédito do BNDES sobre firmas de tamanhos diversos. Por fim, Lazzarini et al. (2015) e Bonomo et al. (2015) investigam a conexão causal entre os desembolsos do BNDES e firmas de capital aberto, tipicamente grandes empresas, e não encontram impacto estatisticamente significativo dos empréstimos do BNDES.

$\mathrm{O}$ artigo também se relaciona com uma extensa literatura que investiga os efeitos da ação do BNDES sob diversos aspectos. Por exemplo, Ribeiro e De Negri (2009), Coelho e De Negri (2011), Ottaviano e Lage de Sousa (2014) e Cavalcanti e Vaz (2017) examinam os impactos dos empréstimos do BNDES sobre a produtividade das firmas apoiadas. Pereira (2007), Reis et al.. (2007) e Machado et al. (2011) analisam o impacto do crédito do BNDES sobre o emprego. Silva et al.. (2012), Galettia e Hiratukab (2013) e Alvarez et al.. (2014) investigam o efeito do BNDES sobre as exportações brasileiras. Machado et al.. (2017) quantificam o impacto dos empréstimos do BNDES sobre a inovação das firmas apoiadas.

Por fim, mas não menos importante, o artigo se insere em um contexto de muitas críticas sobre a atuação (histórica e recente) do BNDES. O primeiro conjunto de críticas baseia-se na hipótese da instituição não ter focalizado seus empréstimos em atividades com elevada externalidade positiva, tal como se espera de um banco de desenvolvimento, como é o caso, por exemplo, de alguns segmentos de infraestrutura.

O segundo conjunto de críticas diz respeito à ideia de que o BNDES cresceu demasiadamente nos últimos anos, especialmente no período de vigência do PSI. Segundo essa visão, o aumento do BNDES teria sido disfuncional para os mercados de crédito e de capitais no Brasil, na medida em que seus empréstimos eram financiados com taxas de juros inferiores às de mercado, gerando substituição de fonte, crowding-out e distorções alocativas de capital entre os setores da economia (misallocation).

O terceiro conjunto de críticas afirma que o BNDES aumentou muito seus desembolsos para grandes empresas no passado recente (especialmente após a crise de 2008), o que pode não ser desejável, dada a maior facilidade de grandes empresas de captarem recursos no mercado. Para dialogar com essas críticas em perspectiva de longo prazo, esta pesquisa apresenta dados históricos sobre a atuação do banco.

$\mathrm{O}$ artigo está organizado da seguinte forma. Além desta introdução, a segunda seção explora a composição setorial (agropecuária, indústria, infraestrutura e comércio/serviços) dos financiamentos do BNDES desde 1952. A terceira seção trata do tamanho do BNDES em proporção do PIB e do investimento agregado também desde a sua criação. A quarta seção mostra a composição dos desembolsos do BNDES por 
porte de empresa desde 1990, que é o período em que há dados disponíveis para este tipo de análise. Na quinta seção, são feitas algumas considerações finais.

\section{A COMPOSIÇÃO SETORIAL DO BNDES ENTRE 1952 E 2017}

Uma entrevista com Roberto Campos, um dos fundadores do BNDES, mostra que o objetivo da criação da instituição foi conceber o banco da infraestrutura nacional:

"A ideia original do BNDE era criar um órgão de financiamento da contrapartida. Quando se criou a Comissão Mista Brasil-Estados Unidos, tinha-se em vista organizar um programa de reaparelhamento econômico, dado que a infraestrutura econômica brasileira tinha sido substancialmente delapidada durante a guerra pela escassez de importações e de investimentos. Delapidada em termos de sistema ferroviário, de sistema portuário e de sistema rodoviário"( Projeto Memória 30 anos, entrevista concedida em 27/03/1982).

Será que a pretendida atuação relacionada à infraestrutura se verificou ao longo dos anos? A Tabela 1 resume a composição setorial do BNDES ao longo de toda a sua existência.

Tabela 1: Composição setorial dos financiamentos do BNDES entre 1952 e 2017

\begin{tabular}{|c|c|c|c|c|}
\hline & Agropecuária & $\begin{array}{c}\text { Comércio/ } \\
\text { Serviços }\end{array}$ & Indústria & Infraestrutura \\
\hline $1952 / 1960$ & $0,0 \%$ & $2,2 \%$ & $28,4 \%$ & $69,4 \%$ \\
\hline $1961 / 1970$ & $0,0 \%$ & $4,1 \%$ & $70,6 \%$ & $25,2 \%$ \\
\hline $1971 / 1980$ & $0,0 \%$ & $5,6 \%$ & $67,4 \%$ & $27,0 \%$ \\
\hline $1981 / 1990$ & $1,2 \%$ & $11,5 \%$ & $56,1 \%$ & $31,2 \%$ \\
\hline $1991 / 2000$ & $11,0 \%$ & $8,3 \%$ & $48,0 \%$ & $32,8 \%$ \\
\hline $2001 / 2010$ & $9,4 \%$ & $10,4 \%$ & $46,6 \%$ & $33,6 \%$ \\
\hline $2011 / 2017$ & $11,3 \%$ & $23,9 \%$ & $28,8 \%$ & $35,9 \%$ \\
\hline
\end{tabular}

Fontes: BNDES (1992) de 1952 a 1980; BNDES (2017) de 1981 a 1990; e Sistema OPE BNDES de 1991 a 2017.

Entre 1952 e 1960, verifica-se que a participação da infraestrutura nas aprovações ${ }^{2}$ do BNDES foi de 69,4\%, o que representa mais de dois terços do total. Os demais setores participaram da seguinte forma: Indústria, 28,4\%; Comércio/Servi-

\footnotetext{
2 Os dados que serão apresentados sobre financiamentos do BNDES dizem respeito: (i) às aprovações do BNDES para o período entre 1952 e 1990; (ii) e aos desembolsos para o período entre 1990 e 2017.
} 
ços, 2,2\%; e Agropecuária, $0 \%$. Essa composição setorial estava claramente alinhada ao objetivo da criação do banco.

Segundo o BNDES (1992), os financiamentos à infraestrutura entre $1952 \mathrm{e}$ 1960 direcionaram-se majoritariamente para dois segmentos: (i) infraestrutura ferroviária, com participação de $41,4 \%$ nas aprovações totais; e (ii) energia elétrica, com participação de $26,8 \%$. Aliás, o primeiro projeto apoiado pelo BNDES, em 1952, foi a Estrada de Ferro Central do Brasil, o que ilustra a importância da infraestrutura ferroviária nesse período ${ }^{3}$. Também é digno de nota que nenhum financiamento para o segmento de infraestrutura rodoviária foi realizado entre 1952 e 1960. Isso é curioso tendo em vista a declaração de Roberto Campos, o contexto do Plano de Metas e a atração da indústria automobilística para o Brasil ${ }^{4}$.

A partir da década de 1960, o BNDES mudou fortemente de rumo. Depoimento dado pelo ex-superintendente da instituição, Sebastião José Martins Soares, sintetiza esse fato: "No começo da década de 1960, houve uma contenção no ritmo de desenvolvimento. Em 1962, foi um ano em que não crescemos, foi um ano de crise. Foi o período em que o Banco, a meu ver, se afirmou. Foi o momento de transformação do Banco de financiador de infraestrutura para banco industrial” (Memórias do Desenvolvimento. Centro Celso Furtado, 2009).

Em meio a um contexto de políticas de industrialização por substituição de importações, levadas a cabo por sucessivos governos, o BNDES passou a focar no desenvolvimento das indústrias de base no país, tornando-se o banco da indústria nacional. Com esse movimento, a participação da indústria nas aprovações do BNDES alcançou $70,6 \%$ na década de 1960 , enquanto a infraestrutura reduziu sua parcela para $25,2 \%$. Já o setor de Comércio e Serviços manteve-se muito pouco relevante e a Agropecuária seguiu com peso irrisório.

Dentre os segmentos da indústria que mais foram apoiados na década de 1960 estão a indústria siderúrgica (com 41,8\% de participação nas aprovações totais) e a indústria de químicos e fertilizantes (com 6,5\% de participação). Esses dados, extraídos de BNDES (1992), atestam a importância do desenvolvimento das indústrias de base para os governos do período.

Na década de 1970, o padrão setorial do BNDES não se alterou de forma significativa. A indústria continuou ocupando a liderança dos financiamentos do banco, enquanto a infraestrutura se manteve como o segundo setor mais relevante. Os setores de comércio e serviços e agropecuário continuaram sendo apoiados de forma residual.

A composição industrial se alterou levemente em relação à década anterior, com queda de participação dos insumos básicos (principalmente pela perda de participação da siderurgia, que passou de $41,8 \%$ para $18,3 \%$ dos empréstimos totais) e aumento de participação de outras atividades industriais (como têxteis e calça-

\footnotetext{
${ }^{3}$ O Projeto Memória BNDES, disponível no site do BNDES, ilustra diversas curiosidades históricas.

${ }^{4}$ De fato, os recursos destinados às rodovias no Plano de Metas foram provenientes diretamente da União. Ver a esse respeito Memórias do Desenvolvimento n. 4 (2010, p. 59).
} 
dos, produtos alimentares, dentre outros, que somadas, passaram de 7,9\% de participação para 16,5\%). A composição dos financiamentos à infraestrutura também se alterou nessa década. Os destaques são a redução de participação dos empréstimos para energia elétrica (de 16,1\% para 11,4\% dos empréstimos totais) e elevação do apoio à infraestrutura de transporte, majoritariamente ferroviário (de 3,0\% para 7,1\%) - ver BNDES (1992) para maiores detalhes.

Nos anos de 1981-1990, a participação setorial do apoio do BNDES apresentou o mesmo ordenamento do decênio anterior, mas há uma clara diversificação no apoio. Em relação à década de 1970, houve uma queda de aproximadamente onze pontos percentuais na participação da indústria e um incremento próximo a seis pontos percentuais no apoio ao setor de comércio e serviços. Da mesma forma, o apoio à agropecuária, apesar de continuar sendo residual, passou a ser de $1,2 \%$ ante um valor nulo nos períodos anteriores. $\mathrm{O}$ aumento no financiamento aos setores agropecuário e de comércio e serviços nos anos 80 indica o início de uma fase em que estes setores passam a representar uma importância relativa maior no apoio do banco 5 .

A década de 1990 é marcada pelo aumento significativo da participação do setor agropecuário, que passa a representar $11 \%$ do apoio do BNDES, o que corresponde a um aumento de quase dez pontos percentuais em relação ao decênio anterior. Essa elevação fez com que a participação somada dos setores agropecuário e de comércio/serviços - historicamente pouco relevante -, passasse de aproximadamente $6 \%$, na década de 1970 , para cerca de $13 \%$, na década seguinte, atingindo $19 \%$ nos anos 1990. A contrapartida desse aumento foi novamente a redução do setor industrial, que, não obstante, continuou sendo bastante importante, representando cerca de metade do apoio do banco. A participação da infraestrutura se manteve, grosso modo, constante, próxima a um terço dos financiamentos.

O perfil setorial dos anos 2001-2010 apresentou estabilidade em relação aos dez anos precedentes. A alteração foi residual, com: (i) leve crescimento do setor de infraestrutura; (ii) pequeno crescimento do setor de comércio e serviços; (iii) pequena redução do setor agropecuário e; (iv) leve redução do setor industrial. No que diz respeito à composição setorial do crédito do BNDES, os dados sugerem

\footnotetext{
${ }^{5}$ Existem claras limitações estatísticas na análise aqui efetuada, devido tanto a possíveis mudanças metodológicas na classificação de determinados setores, quanto ao próprio dinamismo da organização das atividades produtivas, que faz com que atividades que antes eram realizadas em determinado setor passem a ser realizadas em outro. Um exemplo de modificação da organização da atividade produtiva é o processo de terceirização, pois faz com que atividades antes desempenhadas dentro de uma empresa industrial passem a ser contratadas como serviços de terceiros. Assim, mesmo não havendo mudanças nas atividades realizadas na economia como um todo, existe uma mudança de composição setorial (neste exemplo, uma ampliação da participação do setor de comércio e serviços concomitante a uma redução na participação do setor industrial). Feita esta ressalva, a afirmação de que o início dos anos 1980 marca uma fase de maior diversidade no apoio do Banco só é possível pela magnitude do incremento dos setores de agropecuária, comércio e serviços, em relação à década anterior, e de informações adicionais, como o fato desses setores terem apresentado participação relevante nas décadas posteriores.
} 
que os anos de 1991-2010 poderiam ser aglutinados em um único período homogêneo.

O período recente, compreendido pelos anos de 2011 a 2017, apresentou uma mudança significativa na composição do apoio do banco. O grande destaque foi o aumento de participação do setor de comércio e serviços, que salta da casa de $10 \%$, nos anos 2000, para $23,9 \%$, o que configura um incremento de quase 14 pontos percentuais. Dentre outros fatores, esse aumento de participação está relacionado: (i) aos instrumentos PSI e Cartão BNDES, que ampliaram significativamente o apoio ao setor de comércio e serviços; e (ii) ao crescimento das operações feitas pelo BNDES junto à administração pública (leia-se, Estados e Municípios), classificadas pelo BNDES como pertencentes ao setor de comércio e serviços.

O setor industrial, por sua vez, perde cerca de 18 pontos percentuais, passando a representar $28,8 \%$ dos financiamentos do banco. Os demais setores, agropecuário e infraestrutura, aumentaram levemente sua participação em relação ao período precedente. Pode-se dizer que a redução de importância da indústria está associada intimamente ao aumento de importância do setor de comércio e serviços, incluindo a importância de operações com a administração pública. Note, ain$\mathrm{da}$, que a redução de representatividade da indústria fez com que, pela primeira vez desde a década de 1950, o setor de infraestrutura retomasse o protagonismo em termos de participação no apoio da instituição.

Diante do que foi apresentado, pode-se resumir a evolução do apoio do BNDES da seguinte forma: em um primeiro momento, entre 1952 e 1960, os financiamentos se concentraram no setor de infraestrutura, cuja participação representou cerca de $70 \%$ do apoio total; em um segundo momento, que representa meio século de atuação, de 1961 a 2010, a indústria liderou o apoio do banco - ainda que de forma cadente no período -, com o setor de infraestrutura ocupando o segundo lugar (participação variando de $25 \%-35 \%$ ); ainda neste segundo período, destacam-se os aumentos de participação de comércio e serviços entre 1981 e 1990 , e da agropecuária entre 1991 e 2000, que individualmente passaram de um apoio residual para aproximadamente $10 \%$ dos financiamentos do BNDES. Por fim, no período atual, entre 2011 e 2017, houve uma elevação significativa no apoio a comércio e serviços (incluindo o apoio à administração pública), com redução concomitante da indústria. Esse movimento fez com que a infraestrutura retomasse a liderança nos desembolsos do BNDES, ainda que sua participação tenha se elevado apenas marginalmente, para $35,9 \%$ do total. A Figura 1 traz um resumo dessas mudanças de composição desde 1952.

Pode-se dizer, portanto, que a percepção de que o BNDES representa o banco da infraestrutura nacional parece ser mais normativa do que positiva. Em termos históricos, o BNDES deveria ser descrito como o banco da indústria nacional, pois este foi o setor mais representativo no crédito concedido pela instituição durante a maior parte de sua existência. 
Figura 1: Composição setorial dos financiamentos do BNDES entre 1952 e 2017

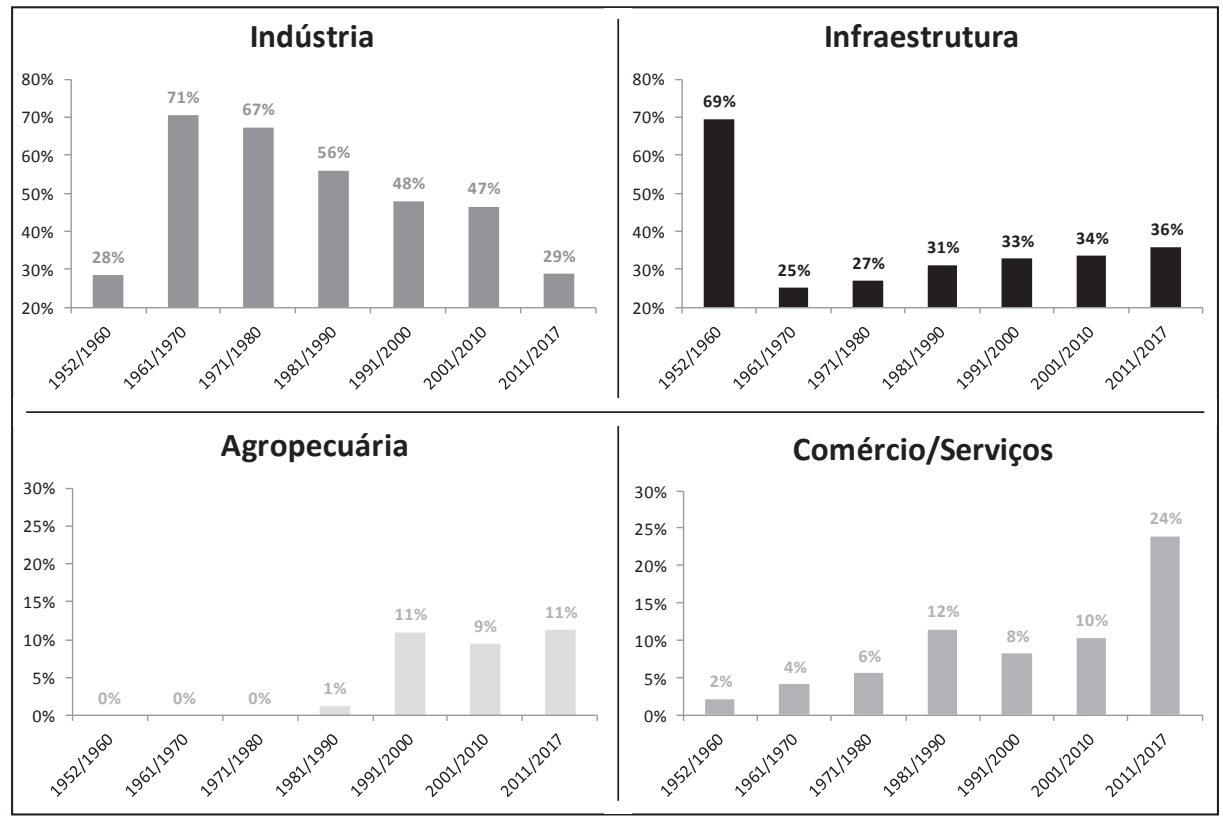

Fonte: BNDES (1992), BNDES (2017) e Sistema OPE BNDES.

\section{O TAMANHO DO BNDES ENTRE 1952 E 2017}

Uma segunda questão relevante acerca da atuação do BNDES diz respeito ao seu tamanho em relação à economia. Para isso, calculamos a razão entre os financiamentos do banco e a formação bruta de capital fixo (FBCF) e a razão entre os financiamentos e o PIB. A Tabela 2 apresenta a evolução dessas duas medidas ao longo do tempo, separadas por quinquênios ${ }^{6}$.

Entre 1952 e 1956, o BNDES apresentou tamanho módico, de 1,2\% da FBCF e $0,2 \%$ do PIB. Nos anos 1957-1963, o banco dobrou de tamanho, mas continuou relativamente modesto em relação à economia. O mesmo ocorreu no período subsequente, entre 1964 e 1973, quando a instituição representou 4,1\% da FBCF e $1,9 \%$ do PIB.

A partir de 1974, o BNDES passa a ter uma presença mais significativa na economia. Nesse período, marcado pelo II Plano Nacional de Desenvolvimento (II PND), auge do processo de industrialização por substituição de importações - que corresponde aproximadamente ao período 1974-78 da Tabela 2 -, o BNDES re-

\footnotetext{
${ }^{6}$ Essa divisão dos períodos em quinquênios está relacionada com a disponibilidade dos dados em Monteiro Filha (1995).
} 
Tabela 2: Apoio total do BNDES como proporção da FBCF e do PIB

\begin{tabular}{|c|c|c|}
\hline & BNDES/FBCF & BNDES/PIB \\
\hline $1952 / 56$ & $1,2 \%$ & $0,2 \%$ \\
\hline $1957 / 63$ & $2,5 \%$ & $0,4 \%$ \\
\hline $1964 / 73$ & $4,1 \%$ & $0,7 \%$ \\
\hline $1974 / 78$ & $8,7 \%$ & $1,9 \%$ \\
\hline $1979 / 81$ & $6,5 \%$ & $1,5 \%$ \\
\hline $1982 / 89$ & $7,6 \%$ & $1,6 \%$ \\
\hline $1990 / 94$ & $3,1 \%$ & $0,6 \%$ \\
\hline $1995 / 99$ & $8,2 \%$ & $1,5 \%$ \\
\hline $2000 / 04$ & $11,7 \%$ & $2,1 \%$ \\
\hline $2005 / 09$ & $15,0 \%$ & $2,7 \%$ \\
\hline $2010 / 14$ & $17,1 \%$ & $3,5 \%$ \\
\hline $2015 / 17$ & $9,7 \%$ & $1,6 \%$ \\
\hline
\end{tabular}

Legenda: O apoio total do BNDES diz respeito ao financiamento total da instituição, incluindo financiamentos que não se direcionam à formação bruta de capital fixo, como capital de giro, exportações, dentre outras.

Fonte: Monteiro Filha (1995) para dados de BNDES/FBCF de 1952-1989; Além (1998) e Livro Verde (2017) para os dados de BNDES/PIB de 1990-1995, tendo as conversões entre BNDES/FBCF e BNDES/PIB sido feitas a partir da taxa de investimento anual do SCN/IBGE. Do ano de 1996 em diante, foram utilizados dados do BNDES e SCN/IBGE.

presentou $8,7 \%$ da FBCF e 1,9\% do PIB, mais que dobrando de tamanho em relação ao período precedente. Aliás, um dos objetivos do II PND consistia em estimular a produção bens de capital e insumos básicos no país e o BNDES foi chamado a atuar com esse direcionamento. Em 1976, por exemplo, 69\% do valor global das operações aprovadas pelo BNDES foram para os programas de insumos básicos e de equipamentos básicos ${ }^{7}$.

Entre 1979 e 1989, que compreende a década perdida - em que o país passou por recorrentes crises de balanço de pagamentos e um processo hiperinflacionário que só viria a ser debelado definitivamente em meados de 1994 -, o banco diminuiu em relação aos anos do II PND, mas se manteve em patamar elevado se comparado ao período 1952 e 1973, com participação de cerca de 1,5\% do PIB e de $7 \%$ da FBCF na média de toda essa década.

Os anos de 1990 e 1994 foram de retração significativa do BNDES, que representou $0,6 \%$ do PIB e apenas 3,1\% da FBCF, padrão similar ao vigente nos períodos anteriores ao II $\mathrm{PND}^{8}$. Essa redução, no entanto, foi passageira. Na segunda metade da década de 90, o BNDES representou 8,2\% da FBCF e 1,6\% do PIB.

\footnotetext{
${ }^{7}$ Dados do Projeto Memória BNDES.

${ }^{8}$ Importante ressaltar que a fonte das informações do período de 1952 e 1989 difere daquela do período pós-1990. Além disso, podem ter ocorrido diversas mudanças metodológicas na contabilização das variáveis econômicas inerentes à análise de períodos longos de tempo, bem como alterações na própria
} 
Os anos compreendidos entre 2000 e 2014 foram de aumento do BNDES. No primeiro quinquênio dos anos 2000, houve ampliação da participação do banco para aproximadamente $12 \%$ da FBCF e $2,1 \%$ do PIB. Os cinco anos seguintes (2005-09) apresentaram nova ampliação dessas duas variáveis, tendo o peso na FBCF ido a $15 \%$ e no PIB a $2,7 \%$.

Os anos de 2010-2014 marcam uma fase única na história do BNDES. Neste período, houve um aumento sem precedentes no tamanho do banco, viabilizado por aportes de recursos do Tesouro Nacional numa escala também sem precedentes (ver Barboza et al. (2017) e Tinoco et al. (2018)). O PSI, criado pelo governo federal como resposta à desaceleração econômica que marcou o período, foi o grande responsável pela ampliação do BNDES entre 2009 e 2015 (ver Machado e Roitman (2015) e Machado, Grimaldi e Albuquerque (2018)). Como consequencia, a participação do BNDES chegou ao seu máximo histórico de 17,1\% da FBCF e de $3,5 \%$ do PIB.

O triênio de 2015-17, por sua vez, foi não apenas de intensa crise econômica doméstica, como também de reversão abrupta da participação do BNDES na economia. O período do auge foi sucedido por um triênio no qual o tamanho do banco foi próximo àquele que vigorou na segunda metade da década de 1990, apresentando participação de $1,6 \%$ do PIB.

Em suma, podemos dividir a evolução do tamanho do BNDES na economia em quatro grandes fases. A primeira, de crescimento e consolidação, vai de 1952 a 1978 e é caracterizada por uma participação crescente do BNDES na economia, atingindo $8,7 \%$ da FBCF e $1,9 \%$ do PIB no período do II PND. A segunda fase comporta os anos de 1979-1994, no qual o banco se reduz sensivelmente, alcançando um tamanho de $3,1 \%$ da FBCF e de $0,6 \%$ do PIB. A terceira fase, que vai de 1995 a 2014, é marcada por um crescimento monotônico da instituição, tanto em termos de participação na FBCF quanto no PIB. O auge dessa fase foi alcançado no período 2010-2014, quando o BNDES atinge sua máxima histórica (17,1\% de participação na FBCF e 3,5\% de participação no PIB). A quarta e última fase corresponde aos anos de crise econômica, entre 2015 a 2017, marcados por uma forte reversão do tamanho do banco, que retorna rapidamente para patamares observados na segunda metade da década de 1990.

Uma forma alternativa de investigar o tamanho do BNDES diz respeito à análise de seus desembolsos em termos reais. Neste caso, é possível analisar os dados até setembro de 2018. Para deflacionar os empréstimos do banco, utilizamos uma média entre o IPA de máquinas e equipamentos e o Índice Nacional da Construção Civil (INCC). Essa escolha se deve ao fato de o BNDES ter entre as suas principais atividades o financiamento a máquinas e equipamentos e o apoio a obras civis e de infraestrutura. A Figura 2 mostra estes dados de 1996 até 2018.

estrutura produtiva (ver nota 5). Não custa lembrar inclusive que ocorreram várias mudanças no padrão monetário brasileiro entre 1985 e 1994. Portanto, as comparações devem ser feitas de forma cautelosa e com ressalvas. A melhor forma de encarar o exercício talvez seja de modo mais qualitativo e menos quantitativo. 


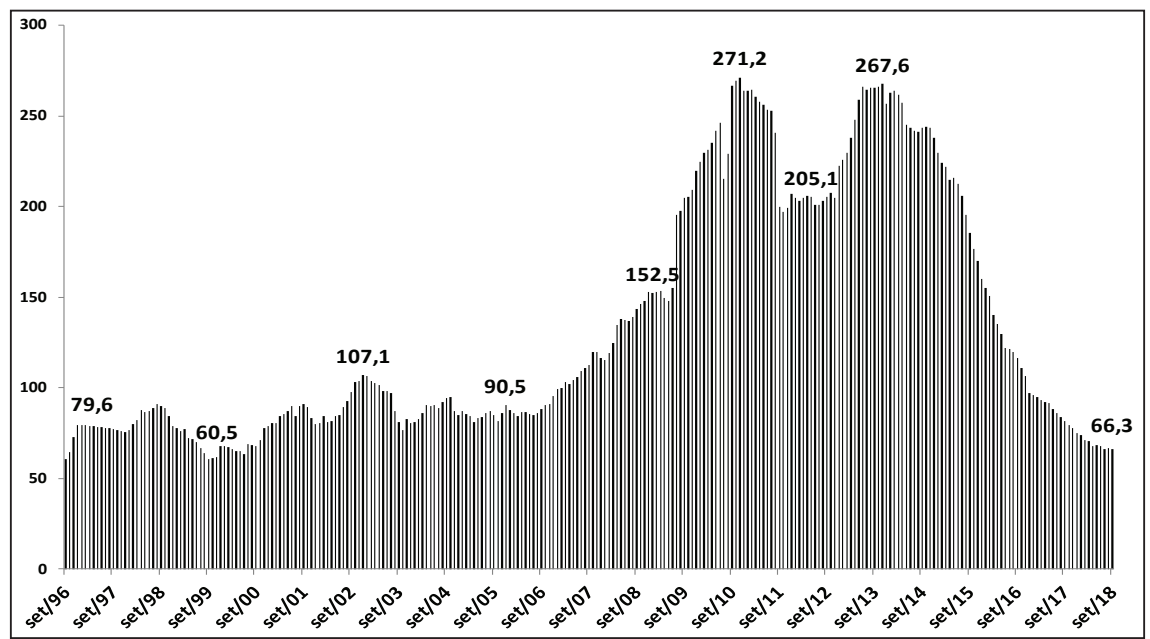

Fonte: Sistema OPE do BNDES. Deflator: média IPA máquinas e equipamentos e INCC. R\$ constantes de set/18.

Como se percebe, o BNDES, em termos reais, atingiu em setembro de 2018 o mesmo tamanho observado na média entre 1996 e 1998. Isso quer dizer que críticas mais atuais ao tamanho do BNDES são tão somente resquícios de um banco do passado, mas que continua vivo no debate público por questões inerciais. A redução de tamanho do BNDES aconteceu de maneira rápida.

Podemos responder, portanto, à pergunta colocada no início do artigo: sim, é verdade que o BNDES cresceu nos anos 2000 de uma forma inédita em sua história, superando em muito o tamanho observado na década de 1970, na vigência do II PND, auge do processo de industrialização por substituição de importações. Esse crescimento ocorreu especialmente entre os anos de 2009 e 2015, no bojo das políticas anticíclicas implementadas pelo governo federal, dentre as quais o grande destaque é o PSI. A participação do BNDES chegou a alcançar 21,4\% da FBCF em 2009 e 4,3\% do PIB em 2010. De 2015 em diante, no entanto, teve início um processo veloz de encolhimento da instituição, que, atualmente, já opera com desembolsos reais compatíveis com o observado na média entre 1996 e 1998.

\section{A PARTICIPAÇÃO DE MPMES E GRANDES EMPRESAS NO BNDES ENTRE 1990 E 2017}

Nesta seção, vamos investigar como se distribuíram historicamente os financiamentos do BNDES em termos de porte de empresa. Sobre esse assunto, infelizmente não existem dados compilados desde a criação do banco. Assim sendo, a análise que segue foi feita desde quando há dados disponíveis, isto é, a partir de 1990. 
Antes de prosseguir, é preciso deixar claro que as estatísticas de porte de empresa aqui reportadas dizem respeito àquelas vigentes no momento da realização de cada operação. E houve algumas reclassificações ao longo do tempo. Em geral, elas foram baseadas em Resoluções do Mercosul ou em simples atualizações monetárias das classificações anteriores. Algumas, no entanto, foram feitas a partir de redefinições de prioridades para o BNDES no apoio a MPMEs9?

O porte de empresas no âmbito do Sistema BNDES está definido em quatro grandes grupos: (i) microempresas; (ii) pequenas empresas; (iii) médias empresas, e; (iv) grandes empresas. De modo a evitar alguns problemas de composição, oriundas de reclassificações de porte ao longo do tempo, especialmente entre micro e pequenas empresas, optamos por fazer a análise em somente dois grupos: (i) micro, pequenas e médias empresas (MPME's); (ii) grandes empresas. A Figura 3 mostra a participação desses dois grupos por quinquênios desde 1990.

Figura 3: Participação Grandes Empresas e MPMEs nos Desembolsos do BNDES

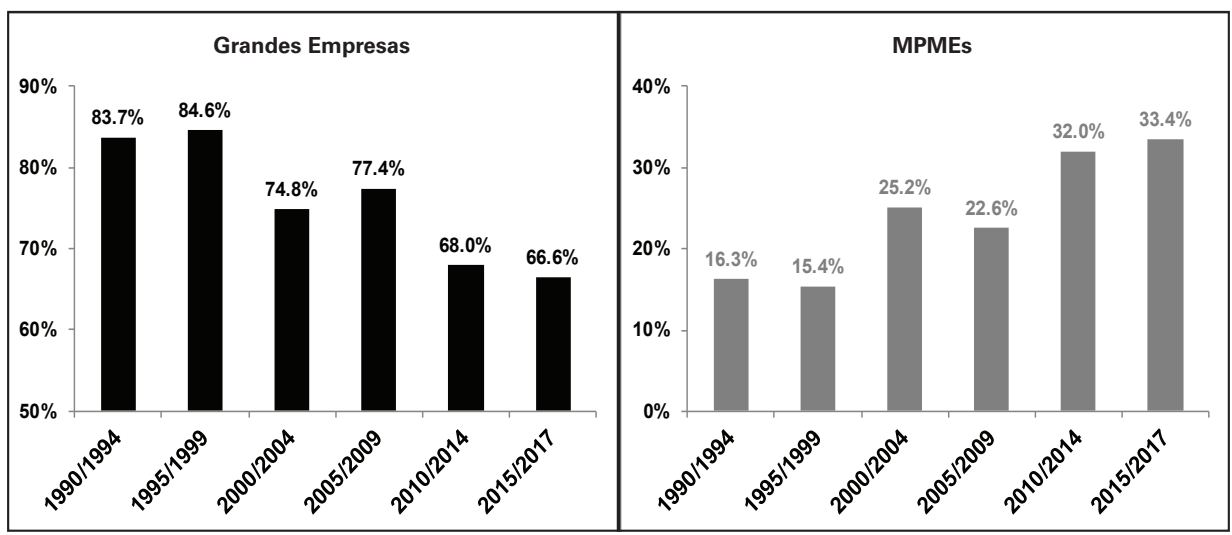

Fonte: Sistema OPE BNDES.

O que se pode notar a partir dos dados disponíveis é que o BNDES tem sido, nos últimos quase trinta anos, um banco financiador majoritariamente de grandes empresas. Esta participação, no entanto, tem diminuído ao longo dos anos e a participação de MPMEs tem aumentado.

É curioso examinar o gráfico acima à luz do senso comum sobre a atuação mais recente do BNDES. O senso comum compartilha uma percepção de que o BNDES apoiou grandes empresas nos últimos anos em uma proporção nunca antes

\footnotetext{
${ }^{9}$ Exemplos não exaustivos de mudanças de alteração de classificação de porte. Em 1997, com base na Lei $\mathrm{n}^{\circ} 8.864$, classificou-se micro e pequenas empresas como aquelas com Receita Operacional Bruta $(\mathrm{ROB})$ inferior ou igual a $\mathrm{R} \$ 637.560,00$, sendo médias e grandes aquelas com ROB superior a tal valor. Em 1999, microempresas foram definidas com ROB inferior ou igual a R $\$ 700$ mil; pequena empresa com ROB superior a $\mathrm{R} \$ 700$ mil e inferior ou igual a $\mathrm{R} \$$ 6.125.000; média empresa com ROB superior a $\mathrm{R}$ \$ 6.125.000 e inferior ou igual a $\mathrm{R} \$ 35.000 .000$; grande empresa com ROB superior a $\mathrm{R} \$$ 35.000.000. Já em 2009, MPMEs eram empresas com ROB anual inferior ou igual a R \$90.000.000,00.
} 
vista na sua história. Talvez algumas operações específicas com grandes empresas realizadas pelo BNDES na última década tenham sido generalizadas como se fossem o padrão de atuação do banco, o que não é correto. Os dados mostram que o BNDES tem atuado cada vez menos (e não mais) com grandes empresas. Como consequência, MPMEs tem ocupado cada vez mais espaço no crédito concedido pelo BNDES. Em 2017, a participação de MPMEs no desembolso total configura um recorde histórico.

A constatação de uma participação crescente de MPMEs nos empréstimos do banco é curiosa em alguns sentidos. Primeiro, porque este tipo de atuação é adequada para um banco de desenvolvimento, na medida em que empresas menores são tipicamente mais restritas à crédito (ver Ambrozio et al. (2017)). Em segundo lugar, visto que o histórico do BNDES foi direcionado, principalmente, para o desenvolvimento da indústria, mas também para o da infraestrutura, existem alguns empecilhos que dificultam a ampliação do apoio a MPMEs, dentre os quais a capilaridade (ou a falta dela) e o limitado número de funcionários para analisar grandes volumes de operações. A forma historicamente encontrada para superar essa limitação foi operar por meio de agentes financeiros parceiros, através das denominadas operações indiretas do BNDES ${ }^{10}$. Além disso, cabe destacar que o PSI também se configurou como um instrumento que desconcentrou os desembolsos do BNDES em favor de MPMEs.

Em virtude dos fatos mencionados, é possível afirmar que o senso comum, que imagina que o BNDES se dedicou, nos últimos anos, a apoiar principalmente grandes empresas não encontra respaldo nas estatísticas de atuação do banco. A verdade é que o período mais recente de existência do BNDES é marcado pela maior participação histórica de MPME’s na composição de seus financiamentos.

\section{CONSIDERAÇÕES FINAIS}

Este trabalho procurou se aprofundar em três temas de elevada importância para o BNDES. Primeiro, buscou investigar a composição setorial dos empréstimos do BNDES desde sua criação, em 1952, com base nos registros históricos de financiamento da instituição. Os dados mostram que a percepção de que o BNDES representa o banco da infraestrutura nacional é mais normativa do que positiva. $\mathrm{O}$

\footnotetext{
${ }^{10}$ Uma importante questão que surge nesse debate diz respeito à capacidade das operações indiretas de aliviarem o problema de restrição de crédito de MPMEs, uma vez que são os próprios agentes financeiros, usuais emprestadores, que concedem esses empréstimos para os clientes finais. Assim sendo, uma agenda de pesquisa que daqui emana é a tentativa de identificar os mecanismos pelos quais e em que medida esse tipo de atuação do BNDES foi capaz de aliviar problemas de restrição de crédito de MPME's. Atualmente, o empenho de alcançar MPMEs pode ser representado pelo desenvolvimento do produto Cartão BNDES, que alcançou número crescente de MPME's entre 2003 e 2014, e que foi desenvolvido através do esforço inovativo do corpo funcional do BNDES (ver, sobre isso, Machado, Parreiras e Peçanha (2011)).
} 
BNDES apenas foi o banco da infraestrutura nacional em sua primeira década de existência e nos anos mais recentes, entre 2010 e 2017. Em termos históricos, no entanto, o BNDES deveria ser descrito como o banco da indústria nacional, pois este foi o setor mais representativo no crédito concedido pela instituição durante a maior parte de sua existência.

O segundo objetivo consistiu em analisar o tamanho do BNDES na economia brasileira desde a sua criação, a partir de sua participação no investimento agregado e no PIB. Os dados mostram que o BNDES aumentou significativamente de tamanho na década de 2000, especialmente entre 2009 e 2014, sob influência do PSI, quando chegou a superar - em muito - o tamanho prevalecente na década de 1970, período que engloba o II PND. Entretanto, a partir de 2015, o tamanho do BNDES voltou a se reduzir sensivelmente, retornando a patamares próximos ao observado na segunda metade da década de 1990. Isso quer dizer que a redução de tamanho do BNDES já aconteceu e, atualmente, os desembolsos reais da instituição estão equivalentes ao observado no início de 1998.

Por fim, o terceiro objetivo do trabalho consistiu em decompor os desembolsos do BNDES, desde 1990, por porte de empresa. Os dados revelam que grandes empresas têm sido cada vez menos - e não mais, como parece ser o senso comum - beneficiadas pelos empréstimos do BNDES. Isso quer dizer que micro, pequenas e médias empresas (MPMEs) têm ganhado cada vez mais participação no crédito concedido pelo BNDES, o que aponta para uma direção desejável para um banco de desenvolvimento.

\section{REFERÊNCIAS BIBLIOGRÁFICAS}

Além, A. C. (1998). O Desempenho do BNDES no Período Recente e as Metas da Política Econômica. Rio de Janeiro, Banco Nacional de Desenvolvimento Econômico e Social.

Alvarez, R. B., D. Prince e S. Kanebley. Júnior (2014). "Financiamento a exportações de produtos manufaturados brasileiros: uma análise microeconométrica”. Prêmio CNI de economia.

Ambrozio, A. M. H. P., F. L. de Sousa, J. P. M. Faleiros, e A. A. Sant'Anna (2017), "Credit scarcity in developing countries: An empirical investigation using Brazilian firm-level data”, EconomiA 18(1), 73-87.

Barboza, Ricardo de Menezes et al.. (2017) “A indústria, o PSI, o BNDES e algumas propostas”. Texto para Discussão BNDES 114. BNDES (1992), BNDES 40 anos: um agente de mudanças. Rio de Janeiro: Banco Nacional de Desenvolvi-mento Econômico e Social .

Bonomo, M., R. D. Brito, e B. Martins, B. (2015), “The after crisis government-driven credit expansion in Brazil: A firm level analysis”. Journal of International Money and Finance 55, 111-134.

Cavalcanti, T. e P. H. Vaz, (2017) "Access to long-term credit and productivity of small and medium firms: A causal evidence”. Economics Letters 150, 21-25.

Coelho, D. and J. A. De Negri (2011) "Impacto do financiamento do BNDES sobre a produtividade das em - presas: Uma aplicação do efeito quantílico de tratamento", Technical Report, ANPEC.

Ellery R; A. Nascimento, e A/ Sachsida, A. (2018). "Avaliando o impacto do Programa de Sustentação do Investimento na taxa de investimento da economia brasileira”. Texto para Discussão IPEA, 2421.

Frischtak, C., C. Pazarbasioglu, S. Byskov, A. Perez e I. Carneiro (2017), “Towards a more effective BNDES”. World Bank Finance and Markets Global Practice 117304. 
Galettia, J. e C. Hiratuka (2013) "Financiamento às exportações: uma avaliação dos impactos dos programas públicos brasileiros". Revista de Economia Contemporânea 17(3), 494-516.

Giambiagi, F., F. Rieche, e M. Amorim (1994). "As finanças do BNDES: evolução recente e tendências". Revista do BNDES 16, 3.

Lazzarini, S. G., A. Musacchio, R. Bandeira-de Mello, e R. Marcon (2015), "What do state-owned development banks do? Evidence from BNDES, 2002-09”. World Development 66, 237-253.

Machado, L., D. S. Grimaldi e B. E. Albuquerque (2018) "Additionality of countercyclical credit: a cost-effectiveness analysis of the Investment Maintenance Program (PSI)" Texto para Discussão BNDES, 129.

Machado, L., M. A. Parreiras e V. R. Peçanha (2011) "Avaliação de impacto do uso do cartão BNDES sobre o emprego nas empresas de menor porte". Revista do BNDES 36, 6.

MACHADO, Luciano; ROITMAN, Fábio Brener (2015). Os efeitos do BNDES PSI sobre o investimento corrente e futuro das firmas industriais. Revista do BNDES, Rio de Janeiro, n. 44, p. 89-122

Monteiro Filha, Dulce Corrêa (1995). “A contribuição do BNDES para a formação da estrutura setorial da indústria brasileira no período 1952/89”. Revista do BNDES, Rio de Janeiro, v. 2, n. 3 , p. $151-166$

Musacchio, A., S. G. Lazzarini, P. Makhoul, e E. Simmons (2017), "The role and impact of Development Banks", World Bank Working Paper.

Oliveira, F. N. et al.. (2014), "Investment of firms in Brazil: do financial restrictions, unexpected monetary shocks and bndes play important roles?", in 'XV Encontro Brasileiro de Finanças'.

Ottaviano, G. I. e F. Lage de Sousa (2014), "Relaxing credit constraints in emerging economies: The impact of public loans on the performance of Brazilian manufacturers", Centro Studi Luca d'Agliano Development Studies Working Paper 369.

Pereira, R. (2007) “Ação do BNDES sobre o emprego formal: efeito nas empresas financiadas", Revista do BNDES 14 (27), 27-42.

Reiff, L. O. A., G. A. G. SANTOS e L. H. R. Rocha (2007), "Emprego formal, qualidade de vida e o papel do BNDES". Revista do BNDES, 14(27), 5-26.

Ribeiro, E. P; J. A. De Negri (2009) "Public credit use and manufacturing productivity in Brazil", in 'Mimeographed document. Available at: http://www. economics. illinois. edu/seminars/development/documents/Ribeiro ProductivityBrazilcausaleffect. pdf'.

Silva, Carlos Eduardo Lobo e (2012), "O impacto do BNDES-exim no tempo de permanência das firmas brasileiras no mercado internacional: uma análise a partir dos microdados”, Planejamento $e$ Políticas Publicas (38), 9-35.

Tinoco, G et al.. (2018) “A renegociação da dívida do BNDES com o Tesouro Nacional: antecedentes, motivação e desdobramentos”. Texto para Discussão BNDES 131. 
ANEXO 1: COMPOSIÇÃO SETORIAL DOS

DESEMBOLSOS DO BNDES DE 1952 A 2017

\begin{tabular}{|c|c|c|c|c|}
\hline & Indústria & Infra & Comercio/Serviços & Agropecuária \\
\hline 1952 & $0,0 \%$ & $100,0 \%$ & $0,0 \%$ & $0,0 \%$ \\
\hline 1953 & $15,5 \%$ & $82,4 \%$ & $2,0 \%$ & $0,0 \%$ \\
\hline 1954 & $8,1 \%$ & $87,7 \%$ & $4,3 \%$ & $0,0 \%$ \\
\hline 1955 & $7,5 \%$ & $90,8 \%$ & $1,7 \%$ & $0,0 \%$ \\
\hline 1956 & $13,3 \%$ & $82,4 \%$ & $4,3 \%$ & $0,0 \%$ \\
\hline 1957 & $24,5 \%$ & $72,2 \%$ & $3,3 \%$ & $0,0 \%$ \\
\hline 1958 & $52,2 \%$ & $45,0 \%$ & $2,8 \%$ & $0,0 \%$ \\
\hline 1959 & $47,9 \%$ & $50,9 \%$ & $1,2 \%$ & $0,0 \%$ \\
\hline 1960 & $86,4 \%$ & $13,3 \%$ & $0,3 \%$ & $0,0 \%$ \\
\hline 1961 & $35,3 \%$ & $61,9 \%$ & $2,9 \%$ & $0,0 \%$ \\
\hline 1962 & $72,9 \%$ & $23,2 \%$ & $3,9 \%$ & $0,0 \%$ \\
\hline 1963 & $92,4 \%$ & $6,5 \%$ & $1,1 \%$ & $0,0 \%$ \\
\hline 1964 & $79,7 \%$ & $20,3 \%$ & $0,0 \%$ & $0,0 \%$ \\
\hline 1965 & $96,1 \%$ & $1,2 \%$ & $2,8 \%$ & $0,0 \%$ \\
\hline 1966 & $86,6 \%$ & $12,5 \%$ & $0,9 \%$ & $0,0 \%$ \\
\hline 1967 & $68,3 \%$ & $25,1 \%$ & $6,6 \%$ & $0,0 \%$ \\
\hline 1968 & $51,8 \%$ & $41,8 \%$ & $6,3 \%$ & $0,0 \%$ \\
\hline 1969 & $61,3 \%$ & $31,7 \%$ & $7,1 \%$ & $0,0 \%$ \\
\hline 1970 & $62,2 \%$ & $28,0 \%$ & $9,8 \%$ & $0,0 \%$ \\
\hline 1971 & $72,4 \%$ & $15,9 \%$ & $11,7 \%$ & $0,0 \%$ \\
\hline 1972 & $70,0 \%$ & $24,9 \%$ & $5,1 \%$ & $0,0 \%$ \\
\hline 1973 & $73,2 \%$ & $17,8 \%$ & $9,0 \%$ & $0,0 \%$ \\
\hline 1974 & $71,7 \%$ & $24,2 \%$ & $4,1 \%$ & $0,0 \%$ \\
\hline 1975 & $74,4 \%$ & $21,0 \%$ & $4,6 \%$ & $0,0 \%$ \\
\hline 1976 & $81,0 \%$ & $16,4 \%$ & $2,6 \%$ & $0,0 \%$ \\
\hline 1977 & $75,3 \%$ & $21,3 \%$ & $3,4 \%$ & $0,0 \%$ \\
\hline 1978 & $39,2 \%$ & $57,2 \%$ & $3,7 \%$ & $0,0 \%$ \\
\hline 1979 & $66,5 \%$ & $25,3 \%$ & $8,2 \%$ & $0,0 \%$ \\
\hline 1980 & $50,2 \%$ & $46,2 \%$ & $3,7 \%$ & $0,0 \%$ \\
\hline 1981 & $55,4 \%$ & $38,0 \%$ & $6,6 \%$ & $0,0 \%$ \\
\hline 1982 & $53,4 \%$ & $38,5 \%$ & $7,9 \%$ & $0,2 \%$ \\
\hline 1983 & $44,3 \%$ & $31,0 \%$ & $24,4 \%$ & $0,2 \%$ \\
\hline 1984 & $43,2 \%$ & $34,7 \%$ & $21,7 \%$ & $0,4 \%$ \\
\hline 1985 & $47,9 \%$ & $38,1 \%$ & $13,1 \%$ & $0,9 \%$ \\
\hline 1986 & $65,0 \%$ & $23,5 \%$ & $10,5 \%$ & $1,0 \%$ \\
\hline 1987 & $55,4 \%$ & $30,4 \%$ & $12,5 \%$ & $1,7 \%$ \\
\hline 1988 & $63,5 \%$ & $27,8 \%$ & $6,0 \%$ & $2,6 \%$ \\
\hline 1989 & $74,3 \%$ & $15,9 \%$ & $5,2 \%$ & $4,6 \%$ \\
\hline 1990 & $71,9 \%$ & $21,4 \%$ & $3,4 \%$ & $3,3 \%$ \\
\hline 1991 & $65,6 \%$ & $22,8 \%$ & $3,0 \%$ & $8,5 \%$ \\
\hline 1992 & $50,2 \%$ & $30,8 \%$ & $3,6 \%$ & $15,3 \%$ \\
\hline 1993 & $45,7 \%$ & $32,3 \%$ & $4,5 \%$ & $17,4 \%$ \\
\hline 1994 & $46,6 \%$ & $28,5 \%$ & $4,7 \%$ & $20,2 \%$ \\
\hline 1995 & $57,2 \%$ & $25,0 \%$ & $7,5 \%$ & $10,3 \%$ \\
\hline 1996 & $45,2 \%$ & $30,9 \%$ & $16,3 \%$ & $7,5 \%$ \\
\hline 1997 & $37,9 \%$ & $45,1 \%$ & $9,3 \%$ & $7,8 \%$ \\
\hline 1998 & $39,4 \%$ & $41,6 \%$ & $11,9 \%$ & $7,1 \%$ \\
\hline 1999 & $46,5 \%$ & $34,4 \%$ & $12,0 \%$ & $7,1 \%$ \\
\hline 2000 & $45,1 \%$ & $36,8 \%$ & $9,9 \%$ & $8,3 \%$ \\
\hline 2001 & $52,1 \%$ & $28,4 \%$ & $8,6 \%$ & $11,0 \%$ \\
\hline 2002 & $46,5 \%$ & $33,9 \%$ & $7,6 \%$ & $12,0 \%$ \\
\hline 2003 & $47,9 \%$ & $28,5 \%$ & $9,8 \%$ & $13,7 \%$ \\
\hline 2004 & $39,6 \%$ & $35,8 \%$ & $7,2 \%$ & $17,4 \%$ \\
\hline 2005 & $49,7 \%$ & $33,8 \%$ & $7,8 \%$ & $8,6 \%$ \\
\hline 2006 & $52,8 \%$ & $30,8 \%$ & $9,7 \%$ & $6,7 \%$ \\
\hline 2007 & $40,8 \%$ & $39,5 \%$ & $12,0 \%$ & $7,7 \%$ \\
\hline 2008 & $42,9 \%$ & $38,6 \%$ & $12,3 \%$ & $6,2 \%$ \\
\hline 2009 & $46,6 \%$ & $35,7 \%$ & $12,7 \%$ & $5,0 \%$ \\
\hline 2010 & $46,8 \%$ & $31,1 \%$ & $16,1 \%$ & $6,0 \%$ \\
\hline 2011 & $31,6 \%$ & $40,4 \%$ & $21,0 \%$ & $7,0 \%$ \\
\hline 2012 & $30,6 \%$ & $33,9 \%$ & $28,2 \%$ & $7,3 \%$ \\
\hline 2013 & $30,5 \%$ & $32,7 \%$ & $27,1 \%$ & $9,8 \%$ \\
\hline 2014 & $26,7 \%$ & $36,7 \%$ & $27,7 \%$ & $8,9 \%$ \\
\hline 2015 & $27,1 \%$ & $40,4 \%$ & $22,4 \%$ & $10,1 \%$ \\
\hline 2016 & $34,2 \%$ & $29,4 \%$ & $20,7 \%$ & $15,7 \%$ \\
\hline 2017 & $21,3 \%$ & $38,0 \%$ & $20,5 \%$ & $20,3 \%$ \\
\hline
\end{tabular}


ANEXO 2: TAMANHO DO BNDES NA

ECONOMIA BRASILEIRA DE 1952 A 2017

\begin{tabular}{|c|c|c|}
\hline & BNDES/FBCF & BNDES/PIB \\
\hline $1952 / 56$ & $1,2 \%$ & $0,2 \%$ \\
\hline $1957 / 63$ & $2,5 \%$ & $0,4 \%$ \\
\hline $1964 / 73$ & $4,1 \%$ & $0,7 \%$ \\
\hline $1974 / 78$ & $8,7 \%$ & $1,9 \%$ \\
\hline $1979 / 81$ & $6,5 \%$ & $1,5 \%$ \\
\hline $1982 / 89$ & $7,6 \%$ & $1,6 \%$ \\
\hline 1990 & $2,4 \%$ & $0,5 \%$ \\
\hline 1991 & $3,3 \%$ & $0,6 \%$ \\
\hline 1992 & $3,3 \%$ & $0,6 \%$ \\
\hline 1993 & $2,6 \%$ & $0,5 \%$ \\
\hline 1994 & $3,9 \%$ & $0,8 \%$ \\
\hline 1995 & $4,9 \%$ & $0,9 \%$ \\
\hline 1996 & $6,1 \%$ & $1,1 \%$ \\
\hline 1997 & $9,8 \%$ & $1,9 \%$ \\
\hline 1998 & $10,2 \%$ & $1,9 \%$ \\
\hline 1999 & $9,8 \%$ & $1,7 \%$ \\
\hline 2000 & $10,5 \%$ & $1,9 \%$ \\
\hline 2001 & $10,4 \%$ & $1,9 \%$ \\
\hline 2002 & $14,0 \%$ & $2,5 \%$ \\
\hline 2003 & $11,8 \%$ & $2,0 \%$ \\
\hline 2004 & $11,7 \%$ & $2,0 \%$ \\
\hline 2005 & $12,7 \%$ & $2,2 \%$ \\
\hline 2006 & $12,4 \%$ & $2,1 \%$ \\
\hline 2007 & $13,3 \%$ & $2,4 \%$ \\
\hline 2008 & $15,1 \%$ & $2,9 \%$ \\
\hline 2009 & $21,4 \%$ & $4,1 \%$ \\
\hline 2010 & $21,1 \%$ & $4,3 \%$ \\
\hline 2011 & $15,4 \%$ & $3,2 \%$ \\
\hline 2012 & $15,6 \%$ & $3,2 \%$ \\
\hline 2013 & $17,1 \%$ & $3,6 \%$ \\
\hline 2014 & $16,4 \%$ & $3,3 \%$ \\
\hline 2015 & $12,7 \%$ & $2,3 \%$ \\
\hline 2016 & $9,1 \%$ & $1,4 \%$ \\
\hline 2017 & $7,2 \%$ & $1,1 \%$ \\
\hline
\end{tabular}

ANEXO 3: PARTICIPAÇÃO

DE GRANDES EMPRESAS E MPMES NO

CRÉDITO DO BNDES

\begin{tabular}{|c|c|c|}
\hline & Grandes & MPMEs \\
\hline 1990 & $93,2 \%$ & $6,8 \%$ \\
\hline 1991 & $89,2 \%$ & $10,8 \%$ \\
\hline 1992 & $82,5 \%$ & $17,5 \%$ \\
\hline 1993 & $80,4 \%$ & $19,6 \%$ \\
\hline 1994 & $73,3 \%$ & $26,7 \%$ \\
\hline 1995 & $77,8 \%$ & $22,2 \%$ \\
\hline 1996 & $84,8 \%$ & $15,2 \%$ \\
\hline 1997 & $87,7 \%$ & $12,3 \%$ \\
\hline 1998 & $87,9 \%$ & $12,1 \%$ \\
\hline 1999 & $84,7 \%$ & $15,3 \%$ \\
\hline 2000 & $80,9 \%$ & $19,1 \%$ \\
\hline 2001 & $77,1 \%$ & $22,9 \%$ \\
\hline 2002 & $77,7 \%$ & $22,3 \%$ \\
\hline 2003 & $70,1 \%$ & $29,9 \%$ \\
\hline 2004 & $68,4 \%$ & $31,6 \%$ \\
\hline 2005 & $75,2 \%$ & $24,8 \%$ \\
\hline 2006 & $78,3 \%$ & $21,7 \%$ \\
\hline 2007 & $75,2 \%$ & $24,8 \%$ \\
\hline 2008 & $76,0 \%$ & $24,0 \%$ \\
\hline 2009 & $82,5 \%$ & $17,5 \%$ \\
\hline 2010 & $72,9 \%$ & $27,1 \%$ \\
\hline 2011 & $64,2 \%$ & $35,8 \%$ \\
\hline 2012 & $67,9 \%$ & $32,1 \%$ \\
\hline 2013 & $66,6 \%$ & $33,4 \%$ \\
\hline 2014 & $68,4 \%$ & $31,6 \%$ \\
\hline 2015 & $72,5 \%$ & $27,5 \%$ \\
\hline 2016 & $69,1 \%$ & $30,9 \%$ \\
\hline 2017 & $58,0 \%$ & $42,0 \%$ \\
\hline
\end{tabular}

